\title{
ANALISIS BEBAN KERJA PADA PEKERJA PROSES PEMBUATAN DIMSUM
}

\author{
Nora Azmi ${ }^{1}$, I Wayan Sukania ${ }^{2}$ dan Joshua Samsudin ${ }^{2}$ \\ ${ }^{1}$ Program Studi Teknik Industri, Universitas Trisakti \\ ${ }^{2}$ Program Studi Teknik Industri, Universitas Tarumanagara \\ e-mail: joshuasamsudin45@gmail.com
}

\begin{abstract}
ABSTRAK
Permasalahan yang dihadapi oleh PT Boga Dimsum Indonesia dikarenakan beberapa jenis dimsum dalam proses pembuatannya masih menggunakan sistem manual yang dapat menimbulkan resiko pada timbulnya cidera. Kondisi ini umumnya terjadi karena posisi kerja pekerja yang kurang nyaman dan durasi pekerjaan yang dilakukan berulang-ulang. Dari hasil identifikasi menggunakan Nordic Body Map questionnaire (NBM) diketahui bahwa pekerjaan pembuatan hakao secara manual merupakan proses yang memiliki resiko paling bayak dikeluhkan pekerja. Hasil kuesioner Nordic Body Map menunjukkan keluhan pekerja terjadi pada bagian bahu, lengan atas, lengan bawah, pergelangan tangan, tangan, punggung, bokong, paha, betis, lutut, dan kaki. Hasil NBM ini mengindikasikan adanya resiko ergonomi pada pekerja. Penelitian ini bertujuan untuk menganalisis tingkat resiko ergonomi yang diterima oleh pekerja pada pembuatan hakao secara manual menggunakan REBA dan Job Stain Index. Pekerjaan memiliki risiko beban kerja tinggi terjadi pada pekerjaan prosses penggulungan hakao. Hal ini dilihat dari skor REBA yang di dapat sebesar 8 dan skor Job Stain Index sebesar 20. Untuk mengatasi hal ini, diberikan 3 usulan perbaikan yaitu membuat alat bantu, perbaikan shift kerja dan perbaikan stasiun kerja. Pengembangan desain stasiun kerja dilakukan dengan metode Morfologi dan Analitycal Hierarchy Process (AHP). Metode AHP digunakan untuk pemilihan konsep meja untuk memproduksi Hakao, khususnya pada proses penggulungan kulit hakao dengan maksud agar dapat mengurangi keluhan pada bagian tubuh karyawan.
\end{abstract}

Kata kunci: Nordic Body Map, REBA, Job Strain, Morfologi, Analitycal Hierarchy Process

\begin{abstract}
The problem faced by PT Boga Dimsum Indonesia due to some kind of dim sum in the manufacturing process is still using manual systems that could pose a risk to the incidence of injury. This condition usually occurs because of the position of workers who work less comfortable and duration of work is done repeatedly. From the results of the identification used NBM note that the work of making hakao manually is a process that has the most stout complained risk workers. The results of the questionnaire Nordic Body Map showing worker complaints occur in the shoulders, upper arms, forearms, wrists, hands, back, buttocks, thighs, calves, knees, and feet. Therefore, the research aimed to analyze the level of risk ergonomics received by workers in the manufacturing hakao manually by REBA, and Job Stain Index. Jobs are at risk for high workload occurring on the job presses hakao rolling. It is seen from REBA score in the can by 8 and Stain Job Index score of 20. To overcome this, given 3 the proposed improvements, namely making tools, repair work shift and repair stations using the morphology and Analytical Hierarchy Process (AHP) to the selection table concept that is aimed at the production hakao especially in rolling the skin hakao intended to reduce complaints on the part of the employee body.
\end{abstract}

Keywords: Nordic Body Map, REBA, Job Strain, Morphology, Analytical Hierarchy Process

\section{PENDAHULUAN}

Di tempat kerja industri, banyak pekerja melakukan pekerjaan proses dalam posisi berdiri untuk jangka waktu yang panjang. Bekerja di posisi berdiri dapat dihubungkan dengan fleksibilitas karena mobilitas posisi kaki dan memiliki besar derajat kebebasan. Posisi ini bekerja mempromosikan pekerja untuk menjadi lebih efisien dan produktif. Namun, berdiri dalam jangka waktu yang panjang dapat mengakibatkan ketidaknyamanan, otot cedera dan kelelahan. Ketika pekerja melakukan pekerjaan berdiri terlalu lama, kontraksi statis terjadi terutama di punggung dan kaki, sehingga mengakibatkan berkurangnya fungsi otot betis. Jika posisi berdiri secara terus menerus dipraktekkan, pekerja akan merasa tidak nyaman dan kelelahan terutama pada otot-otot ekstremitas bawah dan punggung bawah. 
Menurut ILO, setiap tahun ada lebih dari 250 juta kecelakaan ditempat kerja dan lebih dari 160 juta pekerja menjadi sakit karena bahaya ditempat kerja. Terlebih lagi, 1,2 juta pekerja meninggal akibat kecelakaan dan sakit di tempat kerja. Angka menunjukkan, biaya manusia dan sosial dari produksi terlalu tinggi.

Pada penelitian ini dilakukan identifikasi dan analisis resiko keluhan karyawan pada pekerja salah satu perusahaan pembuatan dimsum (PT. Boga Dimsum Indonesia) di Jakarta. Pada perusahaan ini terdapat banyak aktivitas fisik yang dilakukan secara manual (manual handling), dimana salah satunya adalah pada departemen pembuatan hakao. Pemilihan departemen ini adalah karena operator pada departemen ini melakukan banyak gerakan fisik yang berulang-ulang, seperti menggulung, memotong, memipihkan, mengisi dan membungkus. Dari hasil penelitian pendahuluan menggunakan kuesioner Nordic Body Map juga diperoleh bahwa pekerja mengeluh dengan status agak sakit pada 17 titik bagian tubuh dan 4 titik berstatus sakit.

Tujuan penelitian adalah mengetahui keluhan fisik yang dialami oleh para pekerja, mengetahui resiko beban kerja tertinggi pada bagian pembuatan aneka dimsum, memberikan usulan perbaikan yang diberikan untuk perusahaan agar dapat mengurangi beban kerja, mengetahui posisi kerja yang baik bagi proses pembuatan dimsum, memberikan usulan terbaik agar dapat mengurangi resiko beban kerja, dan mengetahui hasil dari implementasi dan menganalisis kembali.

\section{METODE PENELITIAN}

Melalui NBM dapat diketahui bagianbagian otot yang mengalami keluhan dengan tingkat keluhan mulai dari rasa tidak nyaman (agak sakit) sampai sangat sakit [1]. Dengan melihat dan menganalisis peta tubuh (NBM) maka dapat diestimasi jenis dan tingkat keluhan otot skeletal yang dirasakan oleh pekerja.

Rapid Entire Body Assessment (REBA) merupakan sebuah metode yang dikembangkan oleh Dr.Sue Hignett dan Dr. Lynn Mc Atamney yaitu dalam bidang ergonomi yang digunakan secara cepat untuk menilai postur leher, punggung, lengan, pergelangan tangan, dan kaki seorang pekerja [2]. Setelah diperoleh skor REBA, yang benilai 1 sampai 15 menunjukkan level tindakan (action level) sebagai berikut: Action level 0: skor 1 menunjukkan bahwa postur ini sangat diterima dan tidak perlu tindakan. Action level 1: skor 2 atau 3 menunjukkan bahwa mungkin diperlukan pemeriksaan lanjutan. Action level 2: skor 4 sampai 7 menunjukkan bahwa perlu tindakan pemeriksaaan dan perubahan perlu dilakukan. Action level 3 skor 8 sampai 10 menunjukkan bahwa perlu pemeriksaan dan perubahan diperlukan secepatnya. Action level 4: skor 11 sampai 15 menunjukkan bahwa kondisi ini berbahaya maka pemeriksaan dan perubahan diperlukan dengan segera (saat itu juga).

Objek dalam pengukuran Job Strain Index (JSI) diwakili oleh salah satu divisi dalam pembuatan dimsum yaitu divisi hakao dimana dapat diasumsikan bahwa pada divisi inilah yang mempunyai proses pembuatan dengan memiliki keluhan paling besar dan memerlukan keahlian khusus dalam pembuatannya dikarenakan proses yang rumit. Setelah diperoleh skor akhir yang bernilai 1 sampai tak terhingga menunjukkan level tindakan (action level) sebagai berikut: $<3$ menunjukkan bahwa berstatus aman akan cedera yang dialami karyawan, 3 sampai 5 menunjukkan keraguan akan bahaya cedera yang dialami karyawan, 5-7 menunjukkan bahwa adanya kemungkinan berbahaya akan cedera yang dialami oleh karyawan dan $<7$ menunjukkan bahwa cedera yang dialami karyawan sudah berstatus berbahaya dan harus dilakukan perbaikan [3].

AHP dikembangkan Dr. Thomas L. Saaty dari Wharton School of Business pada tahun 1970-an untuk mengorganisasikan informasi dan judgement dalam memiliki alternatif yang paling disukai. Pada dasarnya AHP adalah metode untuk memecahkan suatu masalah yang komplek dan tidak terstruktur kedalam kelompoknya, mengatur kelompok-kelompok tersebut kedalam suatu susunan hierarki, memasukkan nilai numerik sebagai pengganti persepsi manusia dalam melakukan perbandingan relatif dan akhirnya dengan suatu sintesis ditentukan elemen yang mempunyai prioritas tertinggi [4]. 


\section{HASIL DAN PEMBAHASAN}

Tabel 1 Aktivitas Pekerjaan Pembuatan Hakao

\begin{tabular}{|c|c|c|}
\hline Pekerjaan & Dokumentasi & Aktivitas \\
\hline $\begin{array}{l}\text { Penggulung- } \\
\text { an }\end{array}$ & & $\begin{array}{c}\text { Kegiatan } \\
\text { penggulungan } \\
\text { adonan } \\
\text { memperoleh } \\
\text { skor REBA } 8\end{array}$ \\
\hline
\end{tabular}

\begin{tabular}{cc}
\hline \\
Pemotongan
\end{tabular}

Pemipihan

Pengisian $\begin{gathered}\text { Pegisian adonan } \\ \text { yang sudah } \\ \text { dipipihkan } \\ \text { mendapat skor } \\ \text { REBA 3 }\end{gathered}$

Pengukuran beban kerja akan dilakukan kepada 4 orang pekerja pembuatan dimsum dengan 3 aktivitas pekerjaan yang berbeda. Pengumpulan data awal dilakukan dengan menyebarkan kuesioner. Data awal yang dibutuhkan berupa usia, pendidikan terakhir, status, dan lama bekerja pekerja pembuatan dimsum yang dapat dilihat pada Tabel 1 Setelah itu, 3 aktivitas pekerjaan pembuatan dimsum yang berbeda akan dijelaskan pada Tabel 1 .

Berikut adalah hasil analisis dari data yang telah diamati dari proses pembuatan hakao yang dapat dilihat pada Tabel 2.

Tabel 2. Hasil Pengamatan Metode Job Strain

\begin{tabular}{cc} 
Index & \\
\hline Jenis Pekerjaan & Hasil Akhir \\
\hline Penggulungan & 20 \\
Pemotongan & 1,5 \\
Pemipihan & 3 \\
Pengisian & 0,8 \\
Pembungkusan & 2,3 \\
\hline
\end{tabular}

Hasil Analisis dan Harapan dilakukan dengan pengamatan dan wawancara langsung untuk mengetahui permalahan, penyebab dan harapan-harapan pekerja yang dapat mengurangi sakit pada saat bekerja dan juga kebutuhan pekerja. Berikut adalah tabel berisi permasalahan identifikasi, penyebab, dan harapan pekerja serta solusi dapat dilihat pada Tabel 3.

Untuk melakukan perbaikan stasiun kerja diperlukan pengamatan dan wawancara kepada pemilik perusahaan dan juga Head Chef untuk menemukan stasiun kerja yang efisien untuk pekerja. Berikut ini adalah gambar stasiun kerja sebelum perbaikan yang dapat dilihat pada Gambar 1.

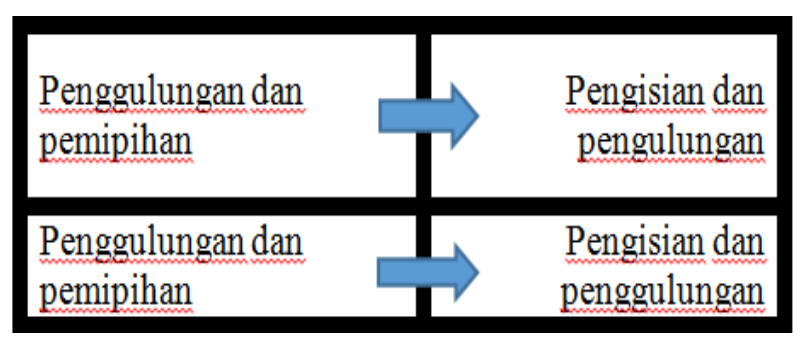

Gambar 1. Kondisi Stasiun Kerja Sebelum Mengalami Perbaikan

Menurut pengamatan dilapangan, data yang didapat menggunakan peta proses regu kerja bahwa sebelum mengalami perbaikan jumlah kegiatan dengan total 64 kali dalam waktu 351,1 detik dan jumlah pekerja yang 
menunggu dengan total 6 kali dalam waktu 26,6 detik.

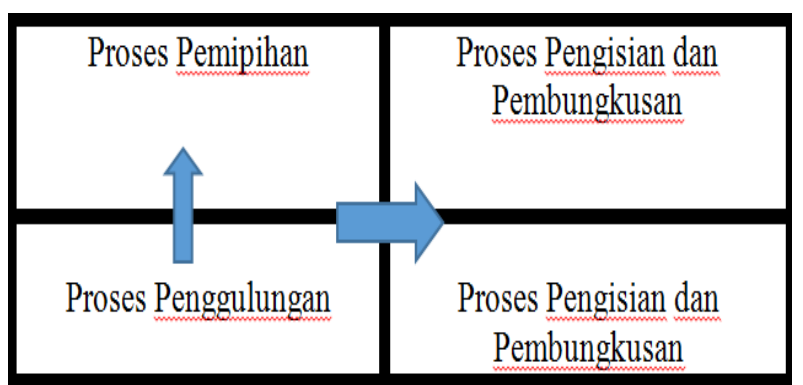

\section{Gambar 2. Kondisi Stasiun Kerja Setelah Mengalami Perbaikan}

Setelah dilakukan perbaikan, berikut adalah gambaran stasiun kerja setelah mengalami perbaikan dapat dilihat pada Gambar 3.

Menurut pengamatan dilapangan, data yang didapat menggunakan peta proses regu kerja bahwa setelah mengalami perbaikan jumlah kegiatan dengan total 61 kali dalam waktu 318,8 detik dan jumlah pekerja yang menunggu dengan total 3 kali dalam waktu 26,4 detik.

Dari kasus yang ditemukan bahwa tidak adanya shift kerja yang ditetapkan oleh perusahaan pada bagian proses pembuatan hakao yang mengakibatkan karyawan harus bekerja selama 46 jam dalam 1 minggu yang dibagi menjadi 6 hari kerja dengan jam kerja dari jam 08.00-18.00 sehingga menimbulkan rasa sakit pada bagian tubuh pekerja dikarenakan pekerjaan yang berulang-ulang sehingga dibuatlah shift kerja berdasarkan pengamatan dan wawancara kepada pemilik perusahaan, pekerja, HRD, dan Head Chef untuk menemukan shift kerja yang pas dan cocok untuk di terapkan, tabel shift kerja dapat dilihat pada Gambar 3.

Dalam merancang alat bantu digunakan

Tabel 3 Hasil Analisis dan Harapan Pekerja

\begin{tabular}{|c|c|c|c|c|}
\hline Analisis & Permasalahan & Penyebab & Harapan Pekerja & Solusi \\
\hline REBA & $\begin{array}{l}\text { Meja kerja terlalu } \\
\text { pendek }\end{array}$ & $\begin{array}{l}\text { Sudut pada bagian } \\
\text { lengan atas membentuk } \\
\text { sudut } 80 \text { o menyebabkan } \\
\text { sakit pada bahu dan } \\
\text { lengan }\end{array}$ & $\begin{array}{l}\text { Mengurangi rasa sakit } \\
\text { dalam bekerja }\end{array}$ & $\begin{array}{l}\text { Menghasilkan alat bantu } \\
\text { agar tidak lagi merasa } \\
\text { sakit pada bahu dang } \\
\text { lengan }\end{array}$ \\
\hline $\begin{array}{l}\text { Job } \\
\text { Stain } \\
\text { Index }\end{array}$ & $\begin{array}{l}\text { Terlalu lama } \\
\text { melalukan } \\
\text { penggulungan Hakao }\end{array}$ & $\begin{array}{l}\text { Pergerakan berulang } \\
\text { ulang menyebabkan } \\
\text { sakit pada bahu }\end{array}$ & $\begin{array}{l}\text { Perbaikan stasiun kerja } \\
\text { dan shift kerja }\end{array}$ & $\begin{array}{l}\text { Melakukan perbaikan } \\
\text { stasiun kerja dan shift } \\
\text { kerja }\end{array}$ \\
\hline
\end{tabular}

\begin{tabular}{|c|c|c|c|c|c|c|c|c|c|c|c|}
\hline \multicolumn{2}{|c|}{$\begin{array}{c}\text { Nama } \\
\text { Karyawan }\end{array}$} & \multirow{2}{*}{ Simon } & \multirow{2}{*}{ Rizky } & \multirow{2}{*}{ Saripudin } & \multirow{2}{*}{ Keterangan } & \multicolumn{2}{|c|}{$\begin{array}{c}\text { Nama } \\
\text { Karyawan }\end{array}$} & \multirow{2}{*}{ Simon } & \multirow{2}{*}{ Rizky } & \multirow{2}{*}{ Saripudin } & \multirow{2}{*}{ Keterangan } \\
\hline Hari & Jam & & & & & Hari & Jam & & & & \\
\hline \multirow{5}{*}{ Senin } & $\begin{array}{l}08.00- \\
10.00\end{array}$ & & & & $\begin{array}{c}\text { Penggulungan dan } \\
\text { Pemotongan }\end{array}$ & \multirow{5}{*}{ Kamis } & $\begin{array}{l}08.00- \\
10.00\end{array}$ & & & & $\begin{array}{l}\text { Penggulungan dan } \\
\text { Pemotongan }\end{array}$ \\
\hline & \begin{tabular}{|l|}
$10.00-$ \\
12.00 \\
\end{tabular} & & & & Pemipihan & & $\begin{array}{l}10.00- \\
12.00 \\
\end{array}$ & & & & Pemipihan \\
\hline & $\begin{array}{l}12.00- \\
13.00\end{array}$ & \multicolumn{4}{|c|}{ ISTIRAHAT } & & $\begin{array}{l}12.00- \\
13.00\end{array}$ & \multicolumn{4}{|c|}{ ISTIRAHAT } \\
\hline & $\begin{array}{l}13.00- \\
15.30\end{array}$ & & & & Pengisian & & $\begin{array}{l}13.00- \\
15.30\end{array}$ & & & & Pengisian \\
\hline & $\begin{array}{l}15.30- \\
18.00\end{array}$ & & & & Pembungkusan & & $\begin{array}{l}15.30- \\
18.00\end{array}$ & & & & Pembungkusan \\
\hline \multirow{5}{*}{ Selasa } & \begin{tabular}{|c|}
$08.00-$ \\
10.00 \\
\end{tabular} & & & & $\begin{array}{c}\text { Penggulungan dan } \\
\text { Pemotongan }\end{array}$ & \multirow{5}{*}{ Jumat } & $\begin{array}{l}08.00- \\
10.00 \\
\end{array}$ & & & & $\begin{array}{c}\text { Penggulungan dan } \\
\text { Pemotongan }\end{array}$ \\
\hline & $\begin{array}{l}10.00- \\
12.00 \\
\end{array}$ & & & & Pemipihan & & $\begin{array}{l}10.00- \\
12.00\end{array}$ & & & & Pemipihan \\
\hline & $\begin{array}{l}12.00- \\
13.00\end{array}$ & & & ISTIRA & AAT & & $\begin{array}{l}12.00- \\
13.00 \\
\end{array}$ & \multicolumn{4}{|c|}{ ISTIRAHAT } \\
\hline & $\begin{array}{l}13.00- \\
15.30\end{array}$ & & & & Pengisian & & $\begin{array}{l}13.00- \\
15.30 \\
\end{array}$ & & & & Pengisian \\
\hline & \begin{tabular}{|l|}
$15.30-$ \\
18.00 \\
\end{tabular} & & & & Pembungkusan & & \begin{tabular}{|l}
$15.30-$ \\
18.00 \\
\end{tabular} & & & & Pembungkusan \\
\hline \multirow{5}{*}{ Rabu } & $\begin{array}{l}08.00- \\
10.00 \\
\end{array}$ & & & & $\begin{array}{c}\text { Penggulungan dan } \\
\text { Pemotongan }\end{array}$ & \multirow{5}{*}{ Sabtu } & $\begin{array}{l}08.00- \\
10.00 \\
\end{array}$ & & & & $\begin{array}{c}\text { Penggulungan dan } \\
\text { Pemotongan }\end{array}$ \\
\hline & $\begin{array}{l}10.00- \\
12.00 \\
\end{array}$ & & & & Pemipihan & & $\begin{array}{l}10.00- \\
12.00\end{array}$ & & & & Pemipihan \\
\hline & $\begin{array}{l}12.00- \\
13.00 \\
\end{array}$ & & & ISTIRA & AAT & & $\begin{array}{l}12.00- \\
13.00 \\
\end{array}$ & \multicolumn{4}{|c|}{ ISTIRAHAT } \\
\hline & $\begin{array}{l}13.00- \\
15.30\end{array}$ & & & & Pengisian & & $\begin{array}{l}13.00- \\
15.30 \\
\end{array}$ & & & & Pengisian \\
\hline & $\begin{array}{l}15.30- \\
18.00\end{array}$ & & & & Pembungkusan & & $\begin{array}{l}15.30- \\
18.00\end{array}$ & & & & Pembungkusan \\
\hline
\end{tabular}

Gambar 3. Shift Kerja yang sudah Diperbaiki 
morfologi chart untuk mengetahui setiap elemen yang terkandung dalam alternatifalternatif yang kemudian dikembangkan untuk perancangan. Peta Morphological Chart meja hakao dapat dilihat pada Gambar 4.

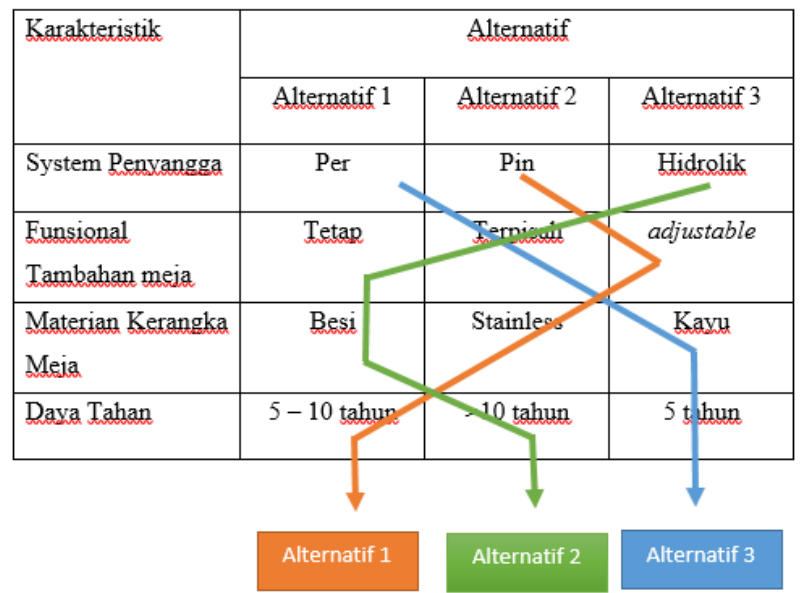

Gambar 4. Peta Morphological Chart

Setiap gambar alternatif meja hakao dapat dilihat pada Gambar 5.

AHP digunakan untuk mengambil keputusan dari alternatif mana yang kemudian akan dikembangkan utuk diimplementasikan. Gambar hirarki AHP meja hakao dapat dilihiat pada Gambar 6.

Kusioner AHP diberikan kepada tiga responden yang terdiri dari Direktur, Executive chef, dan perancang meja hakao. Langkah selanjutnya setelah kuesioner dibagikan adalah membuat matiks pembanding berpasangan dengan geometric mean. Hasil dari table geometric mean kemudian dilakukan iterasi dan dihitung nilai normalisasinya. Kemudian dilakukan iterasi $\mathrm{n}$ dengan menguadratkan matriks pada iterasi pertama, kemudian dihitung kembali nilai normalisasi dan dicari selisih nilai normalisasinya dengan nilai normalisasi iterasi sebelumnya. Apabila selisih nilai normalisasi antar iterasi sudah nol, maka hasil nilai normalisasi iterasi tersebut digunakan sebagai bobot akhir nilai Perhitungan Composite weight AHP Meja dapat dilihat pada Tabel 3.

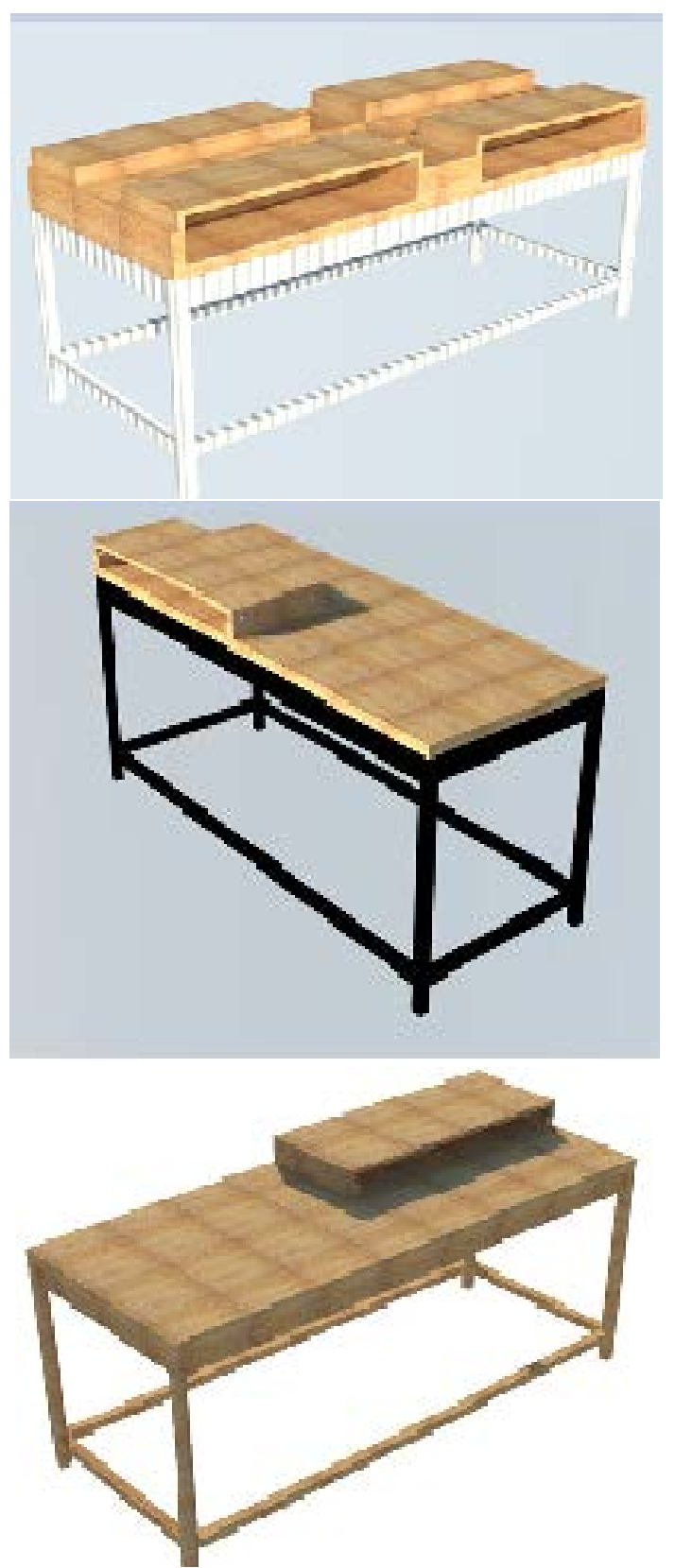

Gambar 5. Alternatif-alternatif Meja Hakao

Tabel 3. Composite Weight

\begin{tabular}{cccccccc}
\hline & & \multicolumn{3}{c}{ Bobot Alternatif } & \multicolumn{3}{c}{ Composite Weight } \\
\cline { 3 - 7 } Elemen & Bobot & Alt 1 & Alt 2 & Alt 3 & 1 & 2 & 3 \\
\hline M & 0,106 & 0,502 & 0,381 & 0,117 & 0,053 & 0,040 & 0,012 \\
F & 0,422 & 0,597 & 0,278 & 0,125 & 0,252 & 0,117 & 0,053 \\
S & 0,372 & 0,422 & 0,426 & 0,163 & 0,153 & 0,159 & 0,061 \\
D & 0,100 & 0,467 & 0,371 & 0,162 & 0,047 & 0,037 & 0,016 \\
\hline \multicolumn{3}{c}{ Total } & & & 0,504 & 0,354 & 0,142 \\
\hline
\end{tabular}




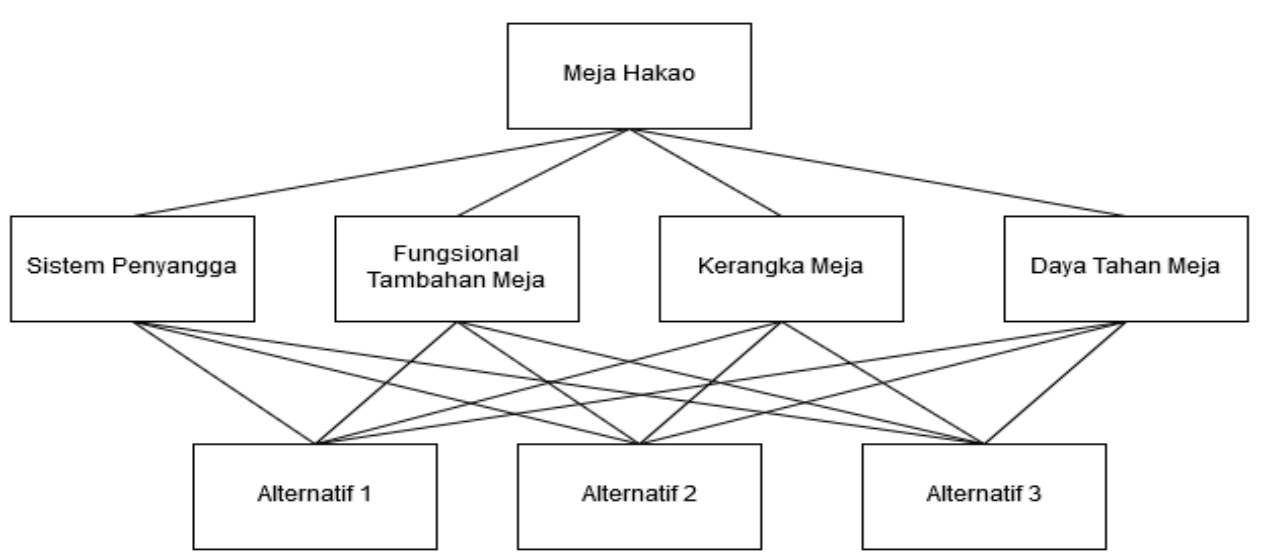

Gambar 6. Analytical Hierarcy Process

Dari hasil perhitungan nilai composite weight diatas dapat disimpulkan bahwa Alternatif 1 yang dipilih.

\section{Dimensi Alat Bantu}

Dimensi alat bantu digunakan untuk menentukan ukuran dalam perancangan alat bantu disesuaikan dengan data antropometri pekerja yang kemudian akan dibandingkan dengan data sekunder dan wawancara kepada Direktur, Executive chef, dan Perancang meja hakao. Data antropometri yang digunakan adalah data antopometri orang Indonesia untuk perancangan meja dapat dilihat pada Tabel 4.

Tabel 4. Data Antropometri Pekerja untuk Perancangan Meja

\begin{tabular}{ccc}
\hline No & $\begin{array}{c}\text { Ukuran Tubuh yang } \\
\text { Digunakan }\end{array}$ & $\begin{array}{c}\text { Ukuran } \\
(\mathrm{mm})\end{array}$ \\
\hline 1 & Tinggi Pinggang & 850 \\
2 & Jakar siku ke ujung jari & 450 \\
\hline
\end{tabular}

Tinggi meja menggunakan tinggi pinggang $850 \mathrm{~mm}$ dimana merupakan standart untuk meja dapur namun ketinggian meja tersebut dapat di extand hingga $950 \mathrm{~mm}$ bila mana suatu saat terjadi perbuahan pekerja. panjang siku ke ujung jari menggunakan presentil 95\% sepanjang 450 mm. Untuk ukuran lebar dan panjang meja di lakukan wawancara kepada Direktur perusahaan, Executive chef dan perancang meja hakao di karenakan meja tersebut akan di pakai untuk pembuatan dimsum lain kedepanya sehingga didapatkan ukuran panjang meja $2400 \mathrm{~mm}$ dan lebar $1200 \mathrm{~mm}$.

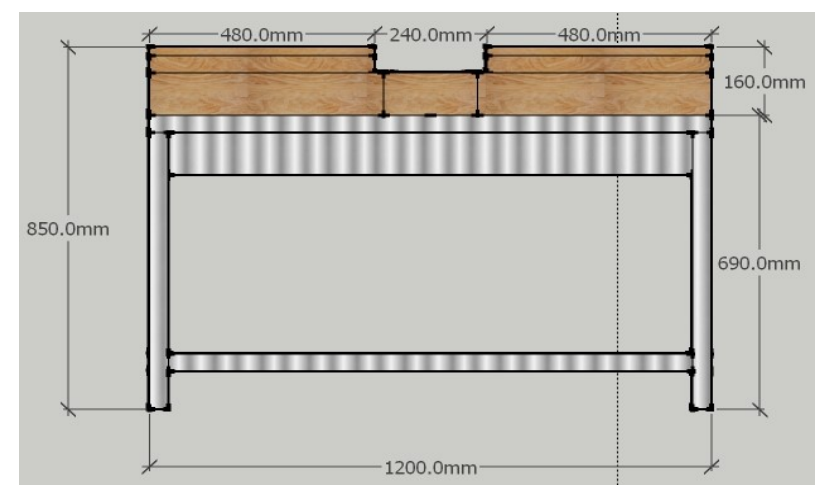

Gambar 7. Tampak Samping

\section{Analisis CATIA}

Setelah mendapatkan konsep dan dimensi yang telah didapatkan, selanjutnya dengan ukurannya telah disesuaikan, dianalisis dan implementasi untuk sementara dengan menggunakan software CATIA untuk mengetahui hasil konsep setelah penerapan. Hasil analisis CATIA dapat dilihat pada Gambar 10.

Berdasarkan hasil perhitungan skor REBA setelah simulasi pada pekerja proses penggulungan, terjadi penurunan skor REBA dari 8 menjadi 2 dengan level risiko rendah. Hasil ini menunjukkan bahwa alat bantu meja hakao yang disimulasikan dapat memperbaiki postur tubuh pekerja dan mengurangi keluhan pekerja. sehingga pekerja terhindar dari risiko cidera pada postur tubuh pekerja. Dengan sudut $125^{\circ}$ kemampuan menekan adonan sudah cukup untuk proses penggulungan pada produksi hakao. 


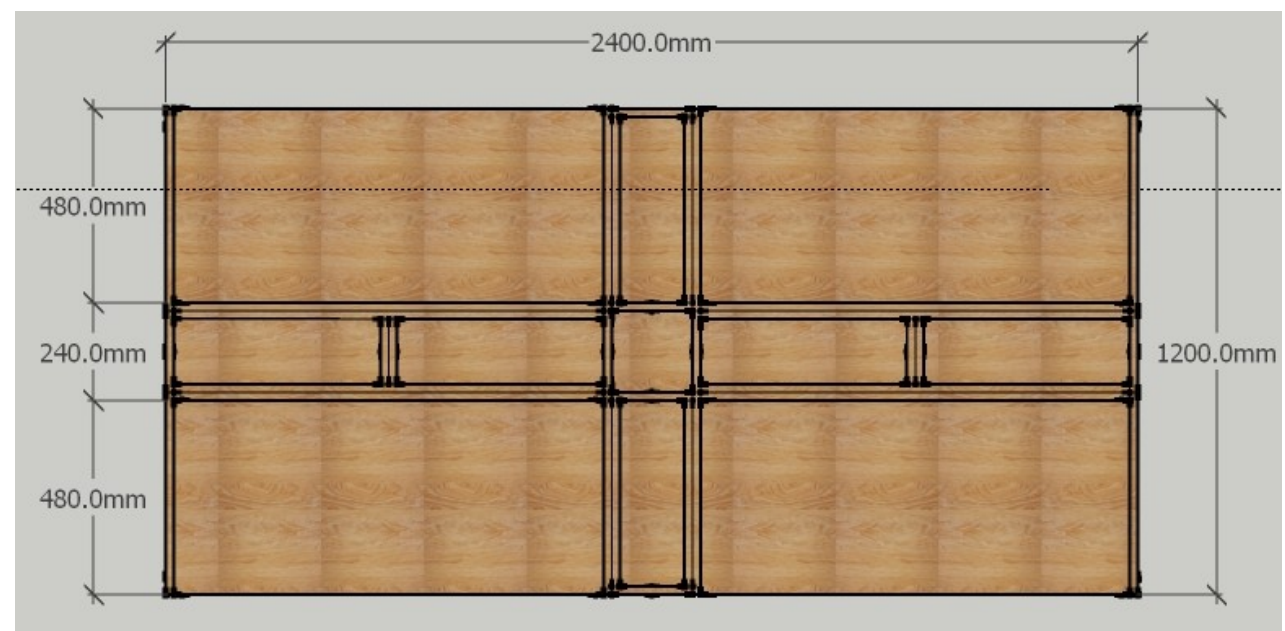

Gambar 8. Tampak Atas

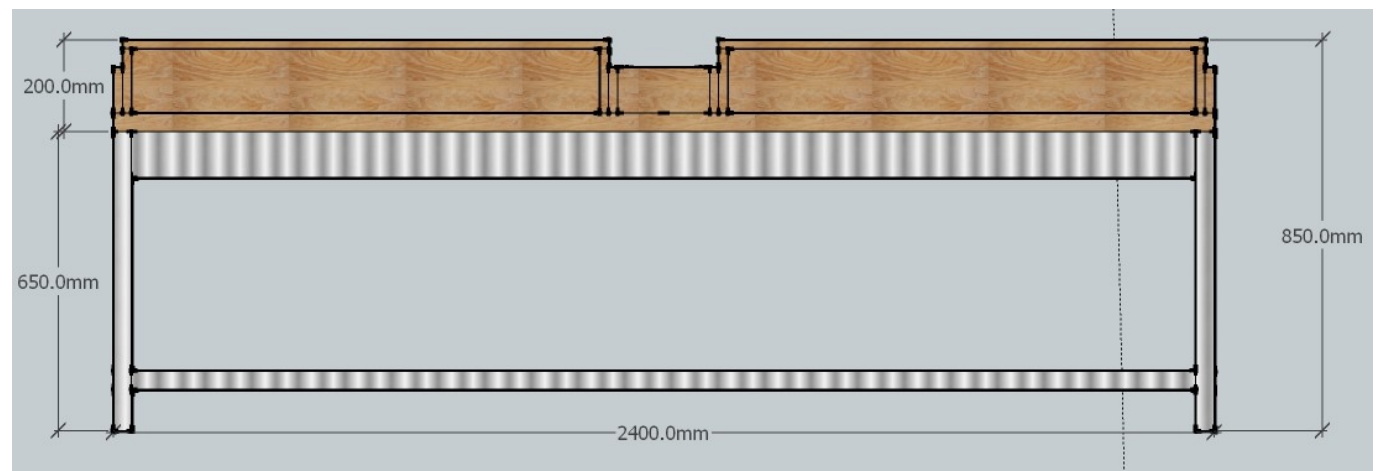

Gambar 9. Tampak Depan

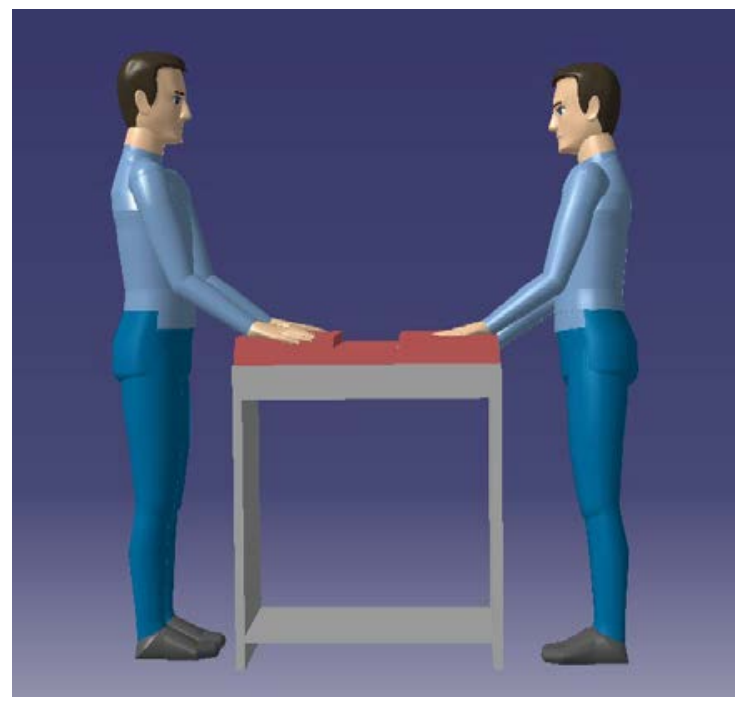

Gambar 10. Analisis Catia

\section{KESIMPULAN}

Berdasarkan qusioner Nordic Bodymap didapatkan keluhan terdapat keluhan berstatus "agak sakit" di 17 bagian tubuh dan yang berstatus "sakit" di 4 bagian tubuh. Berdasarkan analisis REBA didapatkan skor 8 yang berarti memiliki risiko tinggi dan butuh penanganan segera. Berdasarkan analisis Job Strain Index didapatkan skor 20 yang berarti pekerjaan mungkin berbahaya dan butuh penanganan segera. Analisis perbaikan setasiun kerja dengan menggunakan perta regu kerja yang sebelumnya kegiatan dengan total 64 kali dalam waktu 351,1 detik dan jumlah pekerja yang menunggu dengan total 6 kali dalam waktu 26,6 detik. Turun menjadi kegiatan dengan total 61 kali dalam waktu 318,8 detik dan jumlah pekerja yang menunggu dengan total 3 kali dalam waktu 26.4 detik. Melakukan perbaikan shift kerja untuk pekerja. Melalui proses pemilihan konsep dengan metode AHP, didapatkan skor composite weight sebesar 0,5046 sehingga dipilih konsep 1 untuk alternatif meja. Analisis CATIA dilakukan untuk mengetahui hasil implementasi sementara. Berdasarkan analisis CATIA didapatkan skor REBA sebesar 3 yang memiliki skor 3 yang menunjukan adanya penurunan skor setelah dilakukanya implementasi. 


\section{DAFTAR PUSTAKA}

[1] Corlett, E.N., 1992, Static Muscle Loading and the Evaluation of Posture. Edited by Wilson. J.R. \& Corlett, E.N. 1992. Evaluation of Human Work a Practical Ergonomics Methodology. London :Tailor \& Francis.

[2] Sue Hignett and Lynn McAtamney. 2000 Rapid Entire Body Assessment (REBA); Applied Ergonomics. D.L. Kimbler. Clemson University.

[3] Garg, J S. 1995. The Strain Index: A Proposed Method To Analyze Jobs For Risk: American Industrial Hygiene Association Journal.
[4] Saaty, Thomas L. 1993. Pengambilan Keputusan Bagi Para Pemimpin, Proses Hirarki Analitik untuk Pengambilan Keputusan dalam Situasi yang Kompleks. Setiono L, penerjemah; Peniwati K, editor. Jakarta: PT.Pustaka Binaman Pressindo. Terjemahan dari: Decision Making for Leaders the Analytical Hierarchy Process for Decisions in Complex World. 